\title{
Assessment of acute myocardial infarction: current status and recommendations from the North American society for cardiovascular imaging and the European society of cardiac radiology
}

\author{
Arthur E. Stillman • Matthijs Oudkerk • David Bluemke • Jens Bremerich • \\ Fabio P. Esteves · Ernest V. Garcia • Matthias Gutberlet • W. Gregory Hundley • \\ Michael Jerosch-Herold • Dirkjan Kuijpers • Raymond K. Kwong • \\ Eike Nagel • Stamatios Lerakis • John Oshinski • Jean-François Paul • \\ Richard Underwood • Bernd J. Wintersperger • Michael R. Rees
}

Received: 13 September 2010/Accepted: 16 September 2010/Published online: 24 October 2010

(C) The Author(s) 2010. This article is published with open access at Springerlink.com

\begin{abstract}
There are a number of imaging tests that are used in the setting of acute myocardial infarction and acute coronary syndrome. Each has their strengths and limitations. Experts from the European Society of Cardiac Radiology and the North
\end{abstract}

\footnotetext{
A. E. Stillman $(\bowtie) \cdot$ F. P. Esteves · E. V. Garcia ·

S. Lerakis · J. Oshinski

Department of Radiology, Emory University, Atlanta,

GA, USA

e-mail: aestill@emory.edu

M. Oudkerk · D. Kuijpers

Department of Radiology, Groningen University Hospital, Groningen, The Netherlands

D. Bluemke

NIH Clinical Center, National Institute of Biomedical Imaging and Biomedical Engineering, Bethesda, MD,
} USA

\section{J. Bremerich \\ Department of Radiology, University Hospital Basel, Basel, Switzerland}

\section{Gutberlet}

Department of Diagnostic and Interventional Radiology, University of Leipzig, Heart Center, Leipzig, Germany

\section{W. G. Hundley}

Department of Internal Medicine, Section on Cardiology and Radiology, Wake Forest University School of Medicine, Winston-Salem, NC, USA
American Society for Cardiovascular Imaging together with other prominent imagers reviewed the literature. It is clear that there is a definite role for imaging in these patients. While comparative accuracy, convenience and cost have largely guided test

\author{
M. Jerosch-Herold \\ Department of Radiology, Brigham and Women's \\ Hospital, Boston, MA, USA \\ R. K. Kwong \\ Cardiovascular Division, Department of Medicine, \\ Brigham and Women's Hospital Harvard Medical School, \\ Boston, MA, USA \\ E. Nagel \\ King's College London, BHF Center of Research \\ Excellence, NIHR Biomedical Research Center, Division \\ of Imaging Sciences, St. Thomas' Hospital London, \\ London, UK \\ S. Lerakis \\ Department of Cardiology, Emory University, Atlanta, \\ GA, USA \\ J.-F. Paul \\ Department of Radiology, Centre Chirurgical Marie \\ Lannelongue, Le Plessis-Robinson, France \\ R. Underwood \\ Imperial College London, Royal Brompton Hospital, \\ London, UK
}


decisions in the past, the introduction of newer tests is being held to a higher standard which compares patient outcomes. Multicenter randomized comparative effectiveness trials with outcome measures are required.

Keywords Acute myocardial infarction - Acute coronary syndrome $\cdot$ Cardiac imaging

\section{Introduction}

In order to improve the accuracy of the diagnosis of myocardial infarction (MI) for clinicians and clinical scientists, multinational task forces met in 1999-2000 under the auspices of the European Society of Cardiology (ESC), the American College of Cardiology Foundation (ACCF), the American Heart Association (AHA), and the World Heart Federation (WHF) in order to develop a simple, clinically oriented, universal definition for MI that could be employed both in daily clinical practice and in clinical investigation. The report of the original task force was published simultaneously in the European Heart Journal and the Journal of the American College of Cardiology in $2000[1,2]$ and later updated by a joint ESC/ACCF/AHA/WHF task force [3-5].

A consensus report the British Cardiovascular Society developed the definition into three clinical categories [6] (a) Acute Coronary Syndrome (ACS) with clinical myocardial infarction in which there

B. J. Wintersperger

Department of Clinical Radiology, University Hospitals Grosshadern, Ludwig-Maximilians-University, Munich, Germany

M. R. Rees

Department of Radiology, Bristol Royal Infirmary, Bristol, UK

A. E. Stillman - D. Bluemke - M. Jerosch-Herold ·

J. Oshinski

North American Society for Cardiovascular Imaging

URL: www.nasci.org

M. Oudkerk · J. Bremerich · M. Gutberlet .

D. Kuijpers · J.-F. Paul · R. Underwood ·

B. J. Wintersperger · M. R. Rees

European Society of Cardiac Radiology

URL: www.escr.org is a raised troponin greater than $1 \mathrm{ng} / \mathrm{ml} \pm$ raised CK-MB or AccuTn1 greater than $0.5 \mathrm{ng} / \mathrm{ml}$. These patients usually have a complete coronary occlusion, evidence of left ventricular dysfunction and ECG changes of ST elevation, ST depression, or T wave inversion and the risk of death in this syndrome is $12-15 \%$. (b) The patient may have an acute coronary syndrome with myocardial necrosis in which case the troponin although elevated is less than $1 \mathrm{ng} / \mathrm{ml}$. The patient usually has intracoronary thrombus and some evidence of left ventricular dysfunction, the risk of death in this intermediate state is $8-12 \%$. The third syndrome is (c) acute coronary syndrome with unstable angina. In this syndrome the troponin and/or other biomarkers are not raised and the ECG changes of ST depression or elevation may be transient. This syndrome has a reduced risk of death and usually is not associated with left ventricular dysfunction. Coronary plaque disruption and partial coronary occlusion may be present.

After the onset of insufficient myocardial oxygneation, it takes several hours before larger amounts of cell death occur and myocardial necrosis can be identified by macroscopic or microscopic post-mortem examination. Complete necrosis of all myocardial cells within the area at risk requires at least $2-4 \mathrm{~h}$ or longer depending on the presence of collateral circulation to the ischemic zone, persistent or intermittent coronary arterial occlusion, the sensitivity of the myocytes to ischemia, pre-conditioning, and/or, finally, individual demand for myocardial oxygen and nutrients. However, in terms of clinical therapy it is essential that the diagnosis of an acute coronary syndrome should be established quickly and accurately as therapy has to be instigated to limit myocardial necrosis. The concepts of 'door to needle time' for thrombolysis and 'door to balloon time' have been established for primary percutaneous coronary artery interventions (PCI) [7].

In patients presenting with acute myocardial infarction (AMI) present with ST elevation (STEMI) [8], delays in primary PCI increase mortality. The tight window for STEMI allows very little time for additional diagnostic steps including imaging with the exception of the pre PCI coronary angiogram and an emergency room diagnostic cardiac ultrasound.

Myocardial infarction without ST elevation presents a different clinical situation. It is essential that 
the diagnosis is established correctly in order that appropriate treatment can be commenced. In these acute cases the ECG changes may include left bundle branch block or signs of ischemia on the ECG.

Myocardial infarction may be "silent." In the Framingham study, over 30 years 1 in 4 myocardial infarcts were detected because of routine biannual ECG examinations [9] and several recent magnetic resonance trials have demonstrated a significant proportion of unrecognized myocardial infarction. Patients may also present atypically whilst undergoing myocardial infarction and in these cases imaging may play a significant role.

Myocardial infarctions are usually classified by size: microscopic (focal necrosis), small $(<10 \%$ of the left ventricular myocardium), moderate (10-30\% of the LV myocardium), and large ( $>30 \%$ of the LV myocardium), and by location [6]. The pathological identification of myocardial necrosis is made without reference to morphological changes in the coronary arterial tree or to the clinical history.

The "universal" definition of myocardial infarction of the ESC/ACCF/AHA/WHF task force included the use of imaging tests and cardiac biomarkers [3-5]. The imaging evidence of a new loss of myocardium or new regional wall motion abnormality is now a key part of the definition of myocardial infarction. This widened definition offers the opportunity for the use of a range of imaging tests. This paper from the European Society of Cardiac Radiology and the North American Society for Cardiovascular Imaging aims to discuss the use and context of these tests in the diagnosis of acute myocardial infarction and to widen the guidelines for imaging in the light of these new developments.

\section{Physiologic assessment of myocardial infarction}

\section{ECG}

\section{ST elevation myocardial infarction (STEMI)}

Myocardial infarction is stratified according to the presence or absence of elevation of the ST-segment. The presence of ST-segment elevation denotes total occlusion of a coronary artery and identifies patients who would benefit from reperfusion therapy, either with the administration of thrombolytic agents or preferably by primary percutaneous coronary intervention [10].

By definition, in order to diagnose a STEMI, STsegment elevation of greater than $0.1 \mathrm{mV}$ should be present in at least two contiguous limb or precordial leads, with the exclusion of aVR, which "sees" the left ventricular cavity. However, in leads V1-V4, a higher ST-segment elevation of greater than $0.2 \mathrm{mV}$ has greater specificity and diagnostic accuracy. There are two situations where there is total occlusion of an artery causing an AMI, and would benefit from early reperfusion therapy, in which ST-segment elevation may not be present in the 12-lead ECG; AMI of the posterior wall and the new presence of left bundle branch block (LBBB). True posterior AMI is suspected when there is marked ST-segment depression in leads V1-V4 along with tall $\mathrm{R}$ waves and upright $\mathrm{T}$ waves in right precordial leads. In these cases, posterior leads V7 and V8 should demonstrate STsegment elevation and lead to the correct diagnosis. Patients with new or presumably new LBBB caused by $\mathrm{AMI}$ are at high risk; however, the presence of LBBB may lead to delays in diagnosis and management. Three characteristics have been associated with new MI in the presence of LBBB, and, when present, prompt for urgent management; ST elevation greater than or equal to $0.1 \mathrm{mV}$ in leads with a positive QRS, ST depression greater than or equal to $0.1 \mathrm{mV}$ in V1$\mathrm{V} 3$, and ST elevation greater than or equal to $0.5 \mathrm{mV}$ in leads with a negative QRS [11].

It should be mentioned that in the hyperacute phase (during the first 2-30 min) of an AMI the ECG may occasionally demonstrate hyperacute $\mathrm{T}$ waves instead of ST-segment elevation. These $\mathrm{T}$ waves should be distinguished from the peaked $\mathrm{T}$ waves caused by hyperkalemia. Furthermore, it should be emphasized that the presence of ST-segment elevation does not necessarily denote myocardial infarction. Over $90 \%$ of healthy young men have at least $0.1 \mathrm{mV}$ of ST-segment elevation in at least one precordial lead, a normal finding designed as a male pattern [12]. This prevalence declines with age, reaching $30 \%$ in men 76 years of age or older. Other ECG mimics of acute myocardial infarction include early repolarization, acute pericarditis, myocarditis, hyperkalemia, Brugada syndrome, paced rhythm, apical left ventricular ballooning syndrome, and left ventricular aneurysm. The presence of reciprocal changes on the 12 lead ECG may help distinguish 
true acute myocardial infarction from the mimics of acute myocardial infarction. The contour of the ST segment may also be helpful, with a straight or upwardly convex (non-concave) ST segment favouring the diagnosis of acute myocardial infarction.

\section{Estimation of infarct size and reperfusion therapy}

The ECG may be helpful in the estimation of size of myocardium at risk for necrosis. The number of leads showing ST-segment deviation (elevation or depression) and the magnitude of the ST-segment deviation are associated with the size of the ischemic myocardium and with prognosis. The final infarct size, however, also depends on the timing and the efficacy of the reperfusion therapy. ECG has been for long used to assess the efficacy of reperfusion. The extent of resolution of ST-segment elevation is a marker of successful reperfusion either with thrombolytics or with percutaneous coronary intervention [13]. This has been demonstrated using various imaging techniques, including contrast echocardiography [14], radioisotope scintigraphy [15], and magnetic resonance imaging [16]. Resolution of ST-segment elevation after reperfusion therapy is associated with less infarct size and better outcome.

\section{Non-ST elevation acute coronary syndromes (ACS) and unstable angina}

The initial ECG in unstable angina (UA)/non-ST elevation myocardial infarction (NSTEMI) may demonstrate ST-segment depression and/or T wave inversion. The presence of transient ST-segment depression of at least $0.05 \mathrm{mV}$ during an episode of chest pain is strongly suggestive of acute ischemia. The differential diagnosis of NSTEMI over UA, however, can not be made until an elevation of cardiac biomarkers is observed. The absence of ECG changes does not preclude the diagnosis of ACS, since 1-6\% of patients with chest pain will ultimately be found to have NSTEMI and at least $4 \%$ to have UA [17]. The usually transient presence of ECG abnormalities makes the serial ECG assessment essential in identifying possible ACS patients. Furthermore, the comparison of the ECG during the acute episode with an older one helps in the diagnosis.

The number of leads showing ST-segment depression and the magnitude of ST-segment depression may be a sign of extend of ischemia and provide important prognostic information independent of other predictors, such as clinical markers and cardiac biomarkers. The presence of ST-segment depression in at least 3 ECG leads and maximal ST-segment depression of at least $0.2 \mathrm{mV}$ in patients with chest pain is associated with greater likelihood of NSTEMI [18]. Furthermore, the presence of ST-segment deviation is associated with poorer prognosis than isolated $\mathrm{T}$-wave changes [19]. The presence of greater than or equal to $0.2 \mathrm{mV}$ symmetrical precordial $\mathrm{T}$-wave inversion is associated to acute ischemia due to a critical stenosis of the left anterior descending coronary artery (LAD) and it is associated with poor prognosis [20]. NSTEMI that is associated with the above changes will usually be caused by thrombus in a coronary artery, which may unlike a STEMI not be totally occlusive.

\section{Cardiac biomarkers}

For patients with a moderate or high probability of ACS, physicians usually perform assays of markers of myocardial injury such as the cardiac troponins $\mathrm{T}$ or I (cTnT or cTnI) or creatinekinase-MB [3, 21]. The ideal serum marker for myocardial injury would be specific to myocardium, highly sensitive and quantitative with rapidly increased serum levels for early diagnosis. Troponins now are the 'gold standard' method for diagnosis of myocardial infarction [20-23]. Cardiac troponin I and troponin $\mathrm{T}$ are proteins that regulate the calcium-dependent interactions between actin and myosin and have been shown to be very sensitive and specific markers of myocardial cell injury. Different genes encode troponins $\mathrm{T}$ and $\mathrm{I}$ in cardiac muscle, slow skeletal muscle, and fast skeletal muscle; hence, the assays for cardiac troponins are more specific than CK-MB for myocardial injury. They start to rise approximately 4-6 h after the onset of ACS and peak at approximately $24 \mathrm{~h}$. Troponin measurements remain elevated for 7-14 days after the onset of the pain, giving long diagnostic window. An increased value of elevated troponin is assessed as a measurement exceeding the 99th percentile of a normal specificity for AMI. In addition, troponin I provides a higher degree of test specificity than troponin T. Blood samples should be taken on the first hours of the pain onset, 6-9 h later and another sample between 12 and $24 \mathrm{~h}$ if the previous measurements were not elevated but the 
clinical suspicion was high [21]. Even low-level increases of cardiac troponin are associated with an increased rate of recurrent cardiovascular events.

\section{Catheter based angiography}

With the rapid development of primary angioplasty catheter angiography and percutaneous intervention have become central to the diagnostic and treatment of myocardial infarction. Primary PCI (percutaneous coronary intervention) is superior to fibrinolytic therapy in reducing the rates of death, reinfarction, intracranial bleeding, reocclusion of the infarct artery, and recurrent ischemia (even when interhospital transport to a PCI-capable center is required) when performed in a timely fashion by experienced centres [24-30]. If a primary angioplasty protocol is being followed after an ECG based diagnosis of STEMI, the patient is transferred within the door-to-balloon time to a cardiac catheter laboratory. Imaging studies after PCI for STEMI have the possibility of adding value by defining risk stratification. The feasibility and safety of performing cardiac magnetic resonance (CMR) in the hyperacute phase of STEMI was recently verified in a series of 64 patients after PPCI (primary percutaneous coronary intervention)[31].

If primary angioplasty is not available, thrombolysis is the next treatment of choice following which if there is incomplete resolution of the chest pain and ECG changes, 'rescue angioplasty' is often undertaken. On a world wide basis fibrinolytic therapy is the most common treatment for STEMI [26]. However, approximately $20 \%$ of patients who suffer STEMI are not suitable for thrombolysis. Many of these patients, however, do not have access to coronary angioplasty.

There are two general exceptions to the rule that patients who suffer STEMI should undergo primary PCI as the preferred option. These are: (1) patients with STEMI presenting greater than $12 \mathrm{~h}$ from symptom onset without ongoing symptoms of ischemia or clinical instability; and (2) after successful treatment of the culprit artery by PCI or fibrinolysis, revascularization of non-culprit arteries before hospital discharge in patients without clinical instability, with no evidence of recurrent or provokable ischemia, and with a normal LVEF [32]. There is almost certainly a role for non-invasive imaging in these groups of patients who either do not require or do not have access to PCI and catheter angiography.

If the patient suffers a NSTEMI, the patient may also be transferred acutely to the catheter lab as myocardial necrosis also occurs in this condition. The catheter lab therapy follows similar protocols to the treatment of STEMI. Infarct size as measured by acute CMR techniques has been found to smaller in NSTEMI than STEMI [33].

\section{SPECT imaging}

\section{Myocardial perfusion imaging in acute coronary syndrome}

Rest Tc-99 m sestamibi myocardial perfusion single photon emission computed tomography (SPECT) has been used to exclude acute coronary syndrome in ED patients presenting with chest pain syndrome [3441]. The negative predictive value of acute rest myocardial perfusion SPECT for ruling out myocardial infarction in the ED is greater than 99\% [34-36, 39, 41]. Kontos et al. [37] studied patients who presented to the ED within $6 \mathrm{~h}$ of symptoms. Only two of 361 patients $(0.6 \%)$ with a negative test had an acute myocardial infarction within 5 days of admission. Heller et al. [34] showed that only 2 of 204 patients (1\%) with normal images had an acute myocardial infarction during hospitalization in a study involving 6 centers. The negative predictive value of acute rest myocardial perfusion SPECT for future adverse cardiac events is greater than $97 \%$ [34, 39-41]. Udelson et al. [40] prospectively evaluated 1,215 ED patients of 7 different hospitals who were injected with Tc-99 m sestamibi during or within $3 \mathrm{~h}$ of last chest pain episode.

Acute rest myocardial perfusion SPECT has also been shown to reduce health care costs and length of hospital stay in two randomized studies [38, 40]. Stowers et al. reported a median hospital costs of $\$ 1,843$ less for patients in the imaging-guided arm, in which the SPECT imaging results were available to the ED physician. A prospective, randomized study [40] (ERASE Chest Pain) conducted in 7 institutions enrolled 2,475 ED patients who were randomized to either routine management in the ED or a management strategy that included acute rest myocardial perfusion SPECT. Hospitalization was reduced from $52 \%$ with 
routine management strategy to $42 \%$ with imagingguided strategy.

Logistic hurdles have constrained the widespread use of acute rest myocardial perfusion SPECT. The radiotracer injection should take place during symptoms or within few hours of the last chest pain episode for optimal diagnostic value of the test. There should be around the clock availability of the radiopharmaceutical and radiation safety trained staff in the ED. Patients with a previous history of myocardial infarction or coronary intervention are not good candidates for acute rest myocardial perfusion SPECT because a perfusion defect, if present, may represent an old myocardial infarction.

The INSPIRE study was a prospective multinational clinical trial [42-44] designed to evaluate the role of myocardial perfusion SPECT as a risk assessment tool in stable patients within 10 days after acute myocardial infarction. One-day nitrateenhanced rest and adenosine stress myocardial perfusion SPECT was performed in 728 patients with either ST-elevation or non-ST-elevation myocardial infarction. The INSPIRE trial demonstrated that coronary angiography can be safely avoided in stable acute myocardial infarction patients with small $(<20 \%)$ total defect size, minimal ischemia $(<10 \%)$, and preserved LV function. These patients had a low $(<2 \%)$ death/reinfarction event rate at considerably lower associated costs and shorter length of hospital stay compared with the higher-risk patients.

$\mathrm{Rb}-82 \mathrm{PET} / \mathrm{CT}$ in the assessment of myocardial infarction

Hospitals with chest pain observation units have developed alternative methods to triage chest pain patients. After myocardial infarction has been excluded by ECG and biomarkers, stress or rest/ stress myocardial perfusion imaging is performed. A complete rest/stress imaging protocol is best used in patients with a previous history of myocardial infarction and/or revascularization. Rubidium myocardial perfusion positron emission tomography (PET) is an attractive approach in chest pain unit patients. Rubidium is always available because in contrast to other PET perfusion tracers (such as N-13 ammonia and $\mathrm{O}-15$ water) that require an in-house cyclotron for production, rubidium is generator produced. Overall rubidium PET allows better diagnostic accuracy and higher patient throughput when compared to any SPECT protocol.

In a retrospective study 1,177 patients who presented with chest pain to the ED were referred for rest/stress rubidium myocardial perfusion PET [45]. Of the 1,177 patients, $95.4 \%$ had normal images and $4.6 \%$ had abnormal images. Of the abnormal group, $52 \%$ had obstructive CAD at coronary arteriography while $41 \%$ were deemed to have ACS by clinical assessment.

Ischemic memory imaging in acute coronary syndrome

Following an ischemic episode, restoration of coronary blood flow precedes normalization of myocardial metabolism by many hours. This process of metabolic alteration is described as ischemic memory or metabolic stunning. Metabolically stunned myocardium preferentially uses glucose rather than free fatty acids as its primary source of energy. This metabolic phase can be used to evaluate patients in whom the chest pain has subsided upon arrival to the ED. Radioactive glucose (FDG) imaging demonstrates selective tracer uptake in stunned myocardium if the patient is injected at a fasting state [46-48]. Ischemic memory imaging has also been tested with I-123 BMIPP, a free fatty acid analogue [49]. I-123 BMIPP SPECT images are the mirror images of FDG: normal myocardium concentrates I-123 BMIPP whereas stunned myocardium does not.

Two clinical studies by Kawai et al. [50, 51] have shown the potential use of I-123 BMIPP ischemic memory imaging in the ED. The first report [51] included a total of 111 patients who presented with acute coronary syndrome. All patients underwent I123 BMIPP SPECT and coronary angiography within one to 4 days. The sensitivity for obstructive coronary disease or spasm at angiography was $74 \%$ and the specificity was $92 \%$. An ongoing clinical trial in the United States will better define the value of I-123 BMIPP in ED patients.

\section{Echocardiography}

Each year in the United States, about 4 million people undergo evaluation at the Emergency Department for acute chest pain and more than 50\% are admitted to the hospital. Accurate evaluation of patients with 
chest pain without electrocardiographic changes and no elevation of serum levels of cardiac enzymes is difficult because of the low specificity of clinical variables [52-54]. Echocardiography is used not only to triage patients with suspected myocardial infarction, but it is also used in the acute phase of myocardial infarction (MI) as a diagnostic and prognostic tool.

Evaluation of patients with acute chest pain in the emergency room comprises a frequent and sometimes difficult to resolve problem. Echocardiography has an important role in establishing the diagnosis, location, and extent of AMI, diagnosing possible associated mechanical complications of the AMI, and can provide prognostic information that is important for risk stratification. The American Heart Association, and the American Society of Echocardiography (ACC/AHA/ASE) gave a class I recommendation to the use of echocardiography in the diagnosis of suspected acute ischemia or infarction not evident by standard means [55].

Echocardiographic changes in AMI, occur before the onset of electrocardiographic changes or the development of symptoms. Within seconds from the occlusion of the coronary artery, severe ischemia produces regional wall motion abnormalities that can be visualized by cardiac ultrasound [56]. Furthermore the effects of the acute myocardial injury in the diastolic function of the left ventricle are important and can be determined by Echocardiography. Echocardiography can determine the location and extent of the AMI, can access the left ventricular segments involved, the severity of the wall motion abnormality of the segments involved, calculate the wall motion score index (WMSI) and can detect possible mechanical complications.

The availability and use of echo-contrast agents have resulted in better left ventricular opacification and better visualization of the left ventricular endocardium making it easier to access segmental wall motion abnormalities as well as with special protocols visualize myocardial perfusion. The use of contrast has expanded the capability of conventional 2D echocardiography in the assessment of left ventricular function. Echocardiography is very helpful in determining the presence or not of a thrombus in the left ventricle and makes it easier to differentiate the thrombus from an artifact or trabeculations especially in dealing with difficult images. Myocardial contrast echocardiography (MCE) correlates with angiographic methods of perfusion assessment such as myocardial blush grade after thrombolysis [57].

After acute myocardial infarction, low dose dobutamine stress echo can be performed safely in stabilized patients who did not undergo coronary revascularization-under some strict indications: electrical stability, absence of symptoms, no signs of severe cardiac failure, negative enzymes-in order to assess risk stratification, global and regional ventricular function and the presence and extent of residual myocardial ischemia. Especially in patients with low EF due to ischemic cardiomyopathy dobutamine stress echocardiography (DSE) can predict cardiac death, a strong end point in patients who did not undergo early revascularization $[58,59]$. DSE can also localize restenosis or graft occlusion and assess adequacy of revascularization after acute coronary syndrome [59-61].

The extent of myocardium at risk, affects the benefit from reperfusion strategies. In the presence of transmural acute myocardial infarction (ST elevation AMI), cardiac echo will show akinesia or dyskinesia of the myocardial segments, and early reperfusion may lead to the reversal of this effect. Sequential echocardiograhic examinations have shown that the improvement of the myocardial contraction is visible within 24-48 h from reperfusion therapy if the reperfusion is performed early after the event. The persistent akinesia does not indicate failure of thrombolysis. If the reperfusion therapy does not achieve perfusion of $>75 \%$ of the transmural thickness of the myocardial wall, the myocardial segments may remain akinetic. In case that akinesia remains but viability exists, low dose dobutamine stress echo (DSE) will result in a biphasic response with increase in contractility of the previously akinetic myocardial segment with low dose dobutamine. In case of absence of viability, low dose of dobutamine will have no effect on the wall motion of the affected segment. Furthermore, in survivors of a first AMI, DSE allows effective risk stratification on the basis of the presence, severity, and extent the induced ischemia [62]. It is feasible and safe early after uncomplicated myocardial infarction and allows effective risk stratification on the basis of the presence, severity, extent and timing of the induced ischemia. In particular, the risk of death doubles in patients who develop ischemia at high doses of Dobutamine 
infusion and almost quadruples in patients with ischemia at low doses (early stages of the dobutamine stress echo protocol) [63].

\section{Cardiac magnetic resonance imaging}

The assessment of myocardial necrosis by the method of late gadolinium enhancement (LGE) imaging is based on essentially two premises, which were initially established in experimental studies of acute myocardial infarction. The loss of myocyte membrane or sarcolemmal integrity during myocardial ischemia is recognized to be tantamount to the loss cell-viability, and myocardial viability. All available evidence suggests that myocytes can not recover from this disruption of the sarcolemma [64, 65]. The extracellular contrast agents, once they can enter the intra-cellular space, can cause significantly higher contrast enhancement than in normal, viable myocardium, if sufficient time is allowed for the contrast agent to reach an infarct zone after contrast injection. Post-infarct tissue remodeling leads subsequently to a significant increase of the interstitial space. Animal studies comparing Gd-DTPA enhanced MR with the standard of reference $99 \mathrm{~m}$ Tc-DTPA autoradiography showed widely different distribution volumes for extracellular contrast agents in viable and necrotic myocardium, both in acute and chronic myocardial infarction [66, 67].

The distribution volume for Gd-based contrast agents in normal myocardium is on the order of $25 \%$, compared to $70 \%$ or higher in necrotic myocardium [68]. However, the difference of contrast agent concentrations between the different compartments (infarct, viable tissue, blood) is not constant due to complex wash-in and wash-out kinetics. Consequently, the techniques used for LGE imaging have to take into consideration both the time evolution of contrast enhancement of infarcted, normal myocardium, and possibly the blood pool, and also maximize this contrast through the pulse sequence parameters and contrast dosage.

Initial studies had focused on validating the LGE technique in animal models of acute myocardial infarction. A time delay of approximately $20 \mathrm{~min}$ between contrast injection and LGE image acquisition was considered optimal for the detection of myocardial infarction and yielded good agreement with histology [67]. Delivery of the contrast agent to the infarct zone is generally limited by blood flow to the infarct zone for the first couple of minutes after contrast injections, in particular in the absence of recanalization. Despite this, a more recent study by the original pioneers of the LGE technique established that a time delay as short as 5 min post injection may be sufficient for a reliable detection of acute myocardial infarcts, provided the contrast settings for the image acquisition are adjusted [69]. In a recent multicenter trial with a Gd-based contrast agent in patients with acute and chronic infarctions the authors reported that images acquired at 10- and 30-min after contrast injection appeared to yield equal performance for the detection of MI [70]. LGE disappears as the contrast agent is eliminated from the blood pool, with a half time in the blood pool on the order of $30 \mathrm{~min}$ for the Gd-based contrast agents.

Contrast delivery can be impaired during an early phase by microvascular obstruction, which is a result of the blockage of the microcirculation in the infarct zone due to physical obstruction of capillaries by leukocytes, compression of capillaries and hemorrhage. Microvascular obstruction is generally most pronounced at the core of a myocardial infarct. Microvascular obstruction has a clear signature in MRI as a core zone in an infarct that does initially not enhance after contrast injection, but is surrounded within the LV wall by non-viable myocardium with sufficient up-take of contrast agent to show hyperenhancement [71, 72]. The initially dark infarct core then slowly fills in with contrast over a couple of minutes. A typical LGE image of a patient with microvasvcular obstruction after a recent acute myocardial infarction is illustrated in Fig. 1. The exact mode of contrast delivery in areas with microvascular obstruction remains poorly understood but may be related to diffusive rather than convective transport of the contrast agent to the infarct core. The hypoenhancement lasts for approximately $10 \mathrm{~min}$ or less after injection of Gd-based contrast agents, and eventually the core of the infarct also enhances [73]. First pass perfusion imaging may be an even more sensitive method to detect microvascular obstruction [74].

Myocardial edema has been shown to accompany acute myocardial infarction following cellular swelling and increased intracellular osmolarity. The signal intensity of T2-weighted MR techniques have been 

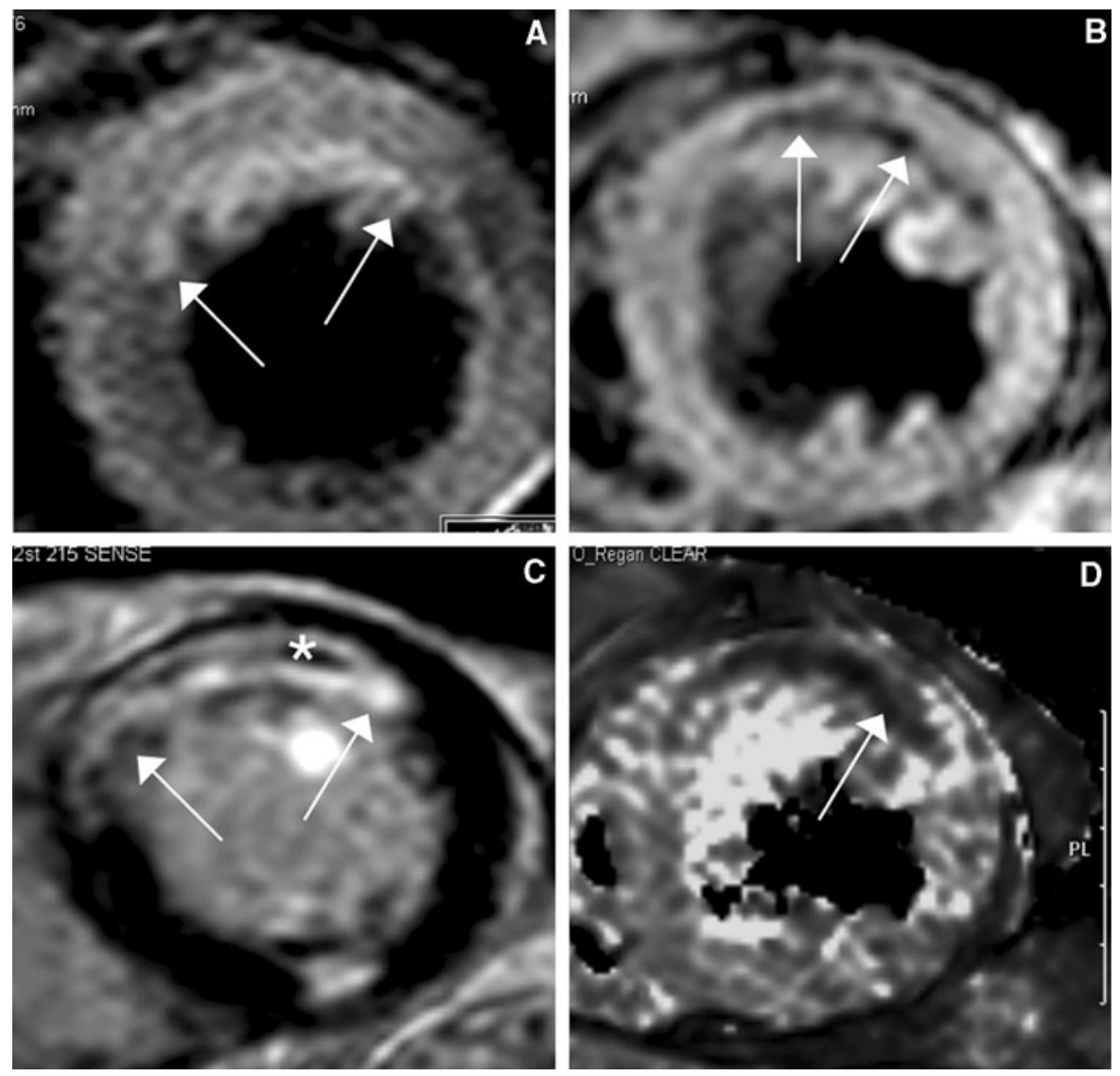

Fig. 1 Example of a 76 year old male patient with an acute myocardial infarction (STEMI) of the anterior wall after acute PCI of the occluded LAD with stent implantation (pain-toballoon time $150 \mathrm{~min}$.). a The water sensitive T2-STIR image demonstrates the edema in the anterior wall (white arrows), c the LGE images demonstrate an almost transmural myocardial infarction (white arrows) with central MVO (asterisk).

shown to correlate with the amount of myocardial water content in experimental infarcts and have proven to reliably visualize myocardial edema in AMI [75-79]. In patients with chronic myocardial infarction (CMI) no increase in SI is exhibited in T2weighted imaging [80]. The extent of the myocardial edema in AMI though not only delineates the infarcted area itself, but also the threatened periinfarct regions the so-called "area at risk" [79, 81, $82]$. Based on its high accuracy ( $>95 \%)$ T2 weighted MR imaging is the current MR approach to identify and differentiate acute from chronic myocardial infarction [79]. It also allows visualizing the effect of revascularization, as most of the area at risk will subsequently become necrotic, if no revascularization is performed. As the image quality of SE or FSE

This indicates almost no myocardial salvage after successful revascularization of the LAD. b shows the $\mathrm{T} 2 *$ image at $\mathrm{TE}=15 \mathrm{~ms}$ and $\mathbf{d}$ the $\mathrm{T} 2 *$ imaging map of the $\mathrm{T} 2 *$ mapping. The central dark area (white arrow) represents pixels with a $\mathrm{T} 2 *$ decay $<20 \mathrm{~ms}$ indicating postreperfusionhemorrhage

based MR techniques may be subject to major variation and these techniques also result in a significant time effort recent technical developments further improve and push the application of $\mathrm{T} 2$ weighted techniques in infarction assessment [81].

A timely and reliable diagnosis of $\mathrm{MI}$ is required for proper treatment of patients in the acute setting, to improve the patients' outcome and to reduce the rate of re-events. A considerable number of patients, though may experience silent MI without noticing and thus during routine checkup there might be no evidence of MI in serum enzymes tests or even ECG $[83,84]$. In a diabetic population in up to $28 \%$ of the patients LGE may be present without any clinical evidence of previous MI [85]. However, these patients would also substantially benefit from 
aggressive secondary prevention measures as for patients with known history of MI. Especially subtle silent subendocardial infarction may be missed by lab testing, ECG or even nuclear medicine tests [86]. In patients presenting with symptoms of acute MI the delineation of possible previous MI is also of major importance and may contribute to further patient triage. Several recent clinical studies have indicated the multi-faceted approach by CMR can characterize the spectrum of disease in patients with acute coronary syndromes with high accuracy. A resting study that consists of myocardial perfusion, cine function, and LGE performed in the emergency room can detect acute coronary syndromes at a high sensitivity and specificity [87]. The addition of T2weighted imaging of area-at-risk improves the specificity to detecting acute coronary syndrome by assessing the acuteness of the ischemic event [88]. Adding stress perfusion enhances the test's sensitivity [89] and has been shown to be a powerful risk stratifying tool to adverse cardiac events within 12 months after hospital presentation [90].

Areas initially involved in acute myocardial infarctions do undergo a steady process of change in their composition within the first days and weeks. This process includes resorption and scar tissue formation with possible ventricular remodeling that may further deteriorate global cardiac function. In the acute setting infarct areas consistently exhibit cell necrosis as well as a considerable myocardial edema; areas of microvascular obstruction (MVO or "noreflow"-zones) resulting from capillary obstruction, edema and endothelial swelling may also be present and are found in a large percentage of ST-segment elevating AMI. In the setting of chronic MI the initially necrotic myocardium is replaced by scar tissue formation with a large extracellular space and less dense cell distribution than in normal myocardium [91]. With the resorption process the size of the infarcted area typically shows a $\sim 20-40 \%$ reduction in the overall volume but also a reduction in its transmural extent although there may be larger variations [92-95]. These changes on the morphology of the infarcted area as well as the change in its functional and metabolic status provide the basics for differentiation of acute from chronic by means of non-invasive imaging modalities. Recent clinical evidence indicates that detection of MVO has important prognostic value beyond infarct size in patients who suffered an acute MI [96]. O'Regan et al. [97] examined 15 patients after acute PCI in acute myocardial infarction using a $\mathrm{T} 2 *$ mapping technique and demonstrated that patients with hemorrhage after revascularization had lower LVEF, lower myocardial salvage [81] greater infarct size and more MVO (Fig. 1).

Areas with wall motion abnormalities but less than $50 \%$ transmural hyperenhancement are generally regarded as having a high likelihood for functional recovery after revascularization [98, 99]. In these areas the remaining myocardium is not necrotic, but in a "stunned" or "hibernating" state. Stunned myocardium is myocardium, which has suffered from severe ischaemia, consequently stopped contracting, but has not been irreversibly damaged. Blood flow to these areas has been restored by revascularization. If this situation becomes chronic as no revascularization has been performed, these areas become hibernating, just preserving their cellular integrity, but not contributing to cardiac function. Low dose dobutamine CMR may be a better predictor of recovery of function following revascularization [100] mainly in patients with intermediate transmurality of myocardial necrosis. But there are also studies available, which show a better prediction of functional recovery after revascularization procedures by using the LGE technique compared to low dose dobutamine stress [101]. Gutberlet et al. [101] demonstrated in 20 patients examined before and 6 months after successful revascularization, that LGE showed the best results for predicting functional recovery compared to low-dose dobutamine stress, wall thickness and also SPECT imaging. The combination of LGE with dobutamine CMR may improve the diagnostic accuracy [102] although this concept is controversial [103].

Dysfunctional myocardium not uncommonly has associated thrombus. A study by Srichi et al. showed that CMR is more sensitive than either transthoracic or transesophageal echocardiography for the detection of ventricular thrombus in patients with ischemic heart disease [104]. Given the risk of embolization in these patients, CMR has a distinct advantage over other techniques.

Furthermore, CMR with the use of edema and inflammation sensitive sequences and LGE allows for the differential diagnosis of myocarditis [105, 106], tako-tsubocardiomyopathy (TTC) [107-109] and 


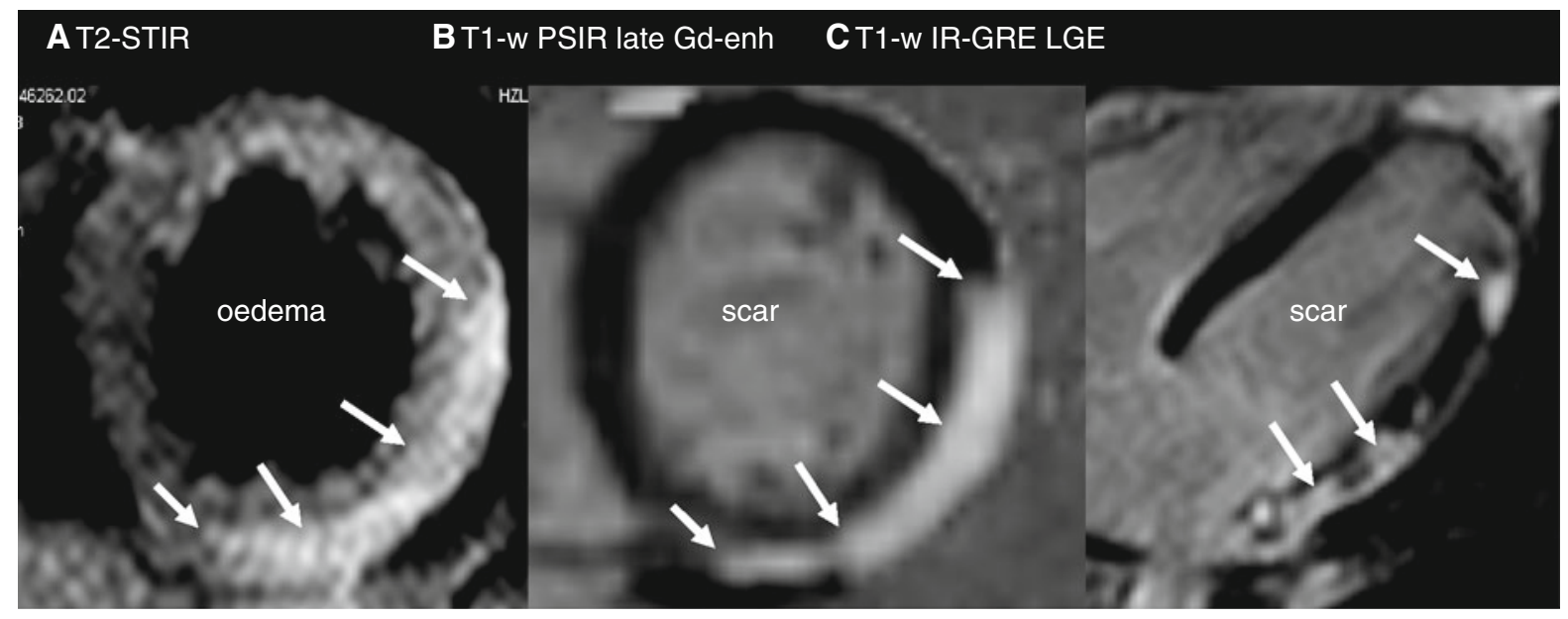

Fig. 2 CMR of a 20 year old man with biopsy proven acute myocarditis. a Demonstrates the typical finding of a subepicardialedema (white arrows) and LGE, b, c indicating acute myocardial inflammation and irreversible cell death

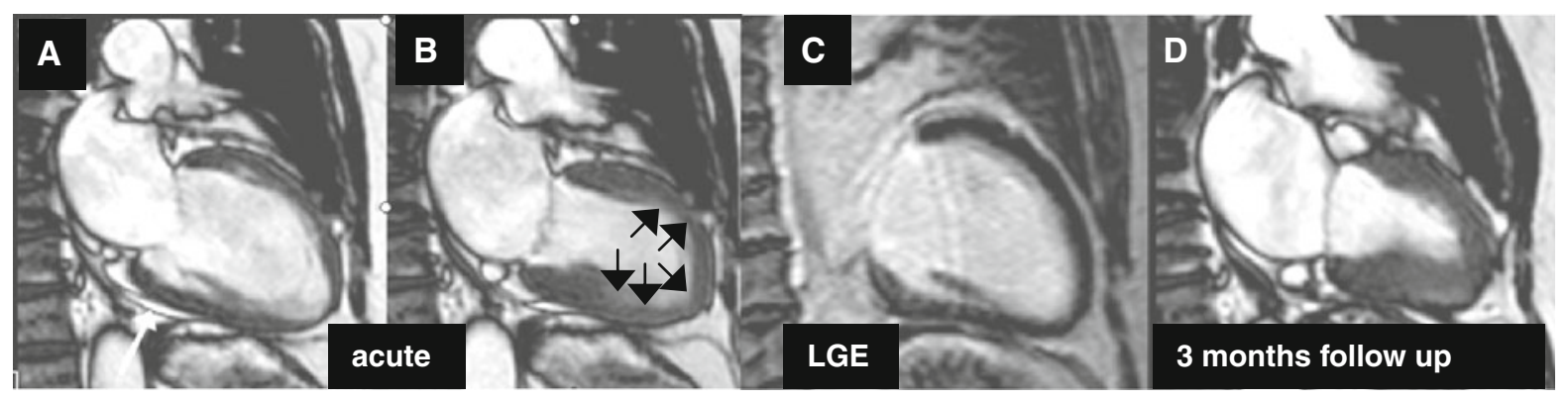

Fig. 3 Cine CMR images of a 40 year old female patient during diastole (a) and systole (b) acquired at acute phase of takotsubocardiomyopathy (TTC) demonstrating apical

acute myocardial infarction, which is crucial because all three can present with similar acute symptoms, ECG-changes, focal wall motion abnormalities and elevated troponin levels, but demonstrate in MRI with different typical features. Acute MI demonstrates with edema and typically subendocardial to transmural LGE (Fig. 1), myocarditis also demonstrates with edema but a usually subepicardial LGE (Fig. 2) and TTC can also appear with edema, but no LGE and shows usually total recovery of ventricular function after a few weeks (Fig. 3).

In summary, CMR is well suited to detect wall motion abnormalities (stunning, hibernation, necrosis), area at risk (with T2 imaging), irreversible damage (necrosis, by LGE), microvascular obstruction (as an independent risk factor), and thrombus in a single examination [74]. Ischemia imaging has no role in patients with acute coronary syndromes but is ballooning (black arrows) in the absence of LGE (c). A repeated Cine CMR 3 months later (d) showed complete normalization of systolic ventricular function

a strong component of the work up of patients presenting with chest pain (Figs. 4, 5).

\section{Cardiac CT}

Cardiac CT has already been established as a highly useful adjunct to percutaneous intervention [110]. With the development of high-speed CT systems, cardiac CT is becoming a first line diagnostic modality in the evaluation of chest pain of unknown origin. This includes atypical presentations of myocardial infarction and presentations that do not result in ECG changes.

Arterial phase imaging is mainly dedicated to coronary CT angiography with identification of possible coronary artery stenoses of coronary plaque formation. A detailed analysis of the myocardial 


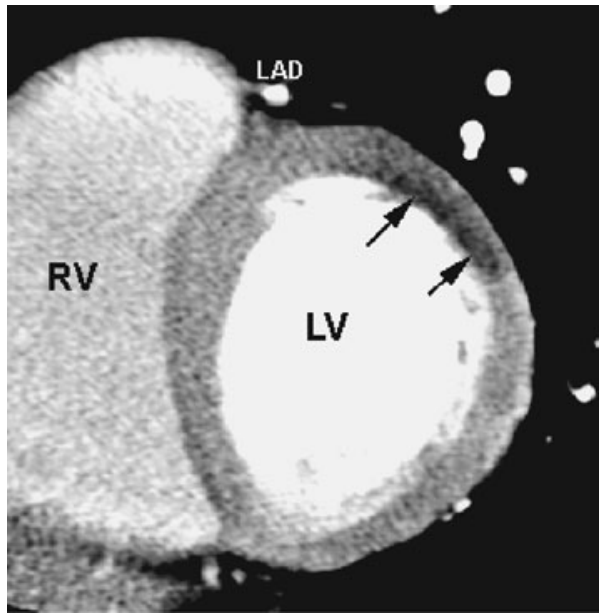

Fig. 4 Example of acute MI due to occlusion of an obtuse marginal artery [126]. First pass MSCT shows local hypoenhancement of the antero-lateral wall. This perfusion defect was leading to find the culprit lesion in a 3 vessel disease patient

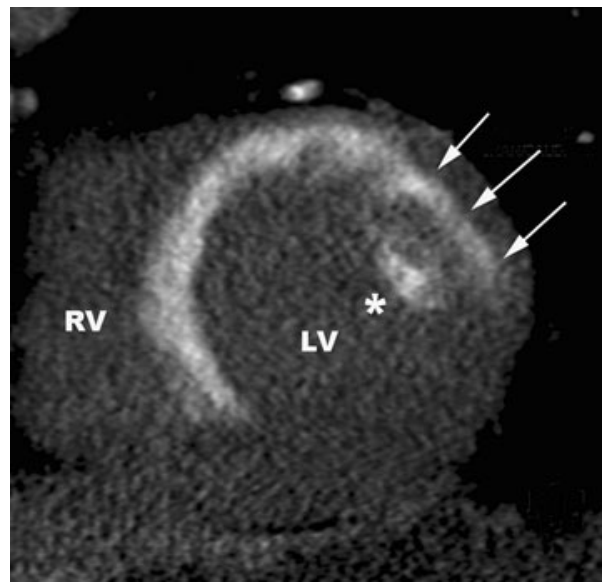

Fig. 5 Post-angioplasty MSCT without reinjection of contrast medium, showing transmuralantero-septal contrast uptake, involving papillary muscle (asterisk). This finding predicts poor recovery of the antero-septal wall

density can give more precise information on possible myocardial perfusion deficits and infarction (Fig. 1). Kachenoura et al. found improved diagnostic accuracy for CCTA in a group of 84 patients when myocardial perfusion was also assessed [111]. A significantly lower attenuation level of infarcted myocardium (any age; acute and chronic) in comparison to normal myocardium has been observed [112-115]. In regard to the differentiation of acute vs. chronic infarctions, some studies showed a tendency to lower attenuation of chronic infarctions compared to acutely injured myocardium $[113,114]$ while others could hardly tell a difference [112]. Inherent differences in CT technology and injection protocols may explain discrepant results. In the acute setting the underlying principle of hypo-attenuation in arterial phase cardiac CT is most likely related to a decreased perfusion while the even lower densities in a chronic infarct setting may be based in changes of the myocardial wall texture with scar tissue development and also possible fatty replacement [113].

Within recent years the principle of "delayed enhancement" imaging as used in MRI has also been systematically been evaluated in cardiac CT. In fact, the principle of "delayed enhancement" has initially been described based on CT imaging in the late 1970s [116]. Recent animal studies have confirmed the ability to accurately evaluate acute and chronic infarctions by means of this technique [117-119] and confirmed in patient studies [117, 120]. CT does not allow to accurately differentiate acute from chronic infarctions solely based on this feature. The accuracy for detection and size of MI appears to be roughly comparable to CMR [112].

Delayed enhancement imaging is realized 5-7 min after injection in acute settings, and later for visualisation of a fibrotic, chronic scar. Low kilovoltage settings $(80 \mathrm{kV}$ for patients under $80 \mathrm{~kg}$ of weight, $100 \mathrm{kV}$ above) are recommended to enhance iodine attenuation and lower radiation dose delivery. Thick MPR images of 5-8 $\mathrm{mm}$ are adequate to visualize myocardium using short-axis, 2 and 4 chambers views. Transmural infarction appears as hyperenhanced myocardium. A central hypoenhanced area, surrounded by contrast enhancement (central core of the infarction) may be observed. This feature corresponds to the no-reflow phenomena, which is also associated with poor recovery of the contractile function. Compared to transmural enhancement, subendocardial changes may be more difficult to detect due to similar contrast between the damaged myocardium and left ventricular cavity, the latter being still partially enhanced 10 min after iodine injection.

Delayed enhancement imaging seems more challenging is case of chronic MI when compared to acute MI. Contrast uptake appears to be weaker compared to acute myocardial infarction. Optimal timing may be different from acute MI because of difference of contrast distribution in case of fibrosis: there is at present time no recommendation for 
optimal visualisation of chronic scar. Thrombus detection in the left ventricle may be facilitated by delayed enhancement imaging, by a better differentiation between enhanced left ventricle wall and nonenhanced thrombus.

Recently, use of cardiac CT just after a coronary angioplasty has been proposed, without needs for reinjection of iodine. This procedure has been shown to be safe and easy to perform. Intra-arterial iodine injected during the angioplasty may be indeed also used as a marker of myocardial damage (Fig. 2). The first study on this topic showed that the transmural pattern of contrast uptake within the myocardium was closely linked to absence of functional recovery (absence of viability) using low-dose dobutamine echocardiography for comparison [121]. In addition, CT findings were found well correlated to MR realized 8 days after [122]. A third paper showed that transmural damage observed just after coronary stenting without reinjection of contrast was able to predict LV remodelling or heart failure at 6 months [123].

It does appear possible to detect ischemia with CT perfusion using adenosine perfusion [124, 125]. In combination with delayed enhanced imaging, it may be possible to provide a comprehensive evaluation for coronary artery stenosis and its functional significance in concert with infarct imaging. Such an approach has not yet been evaluated but may become feasible as radiation dose decreases with more modern CT technology.

\section{Conclusions}

ECG remains the first line test for myocardial infarction together with the use of biomarkers in the acute setting.

Catheter based coronary angiography is used for the diagnosis and treatment of acute coronary syndrome. The role for non-invasive imaging in the acute setting is in patients for which the diagnosis is uncertain, for assessment of resulting mechanical causes of heart failure and for risk assessment. Echo because of its portability can offer critical information very early in AMI.

PET has traditionally been regarded as the reference standard for myocardial viability. Its place has been challenged recently by CMR, which can detect smaller myocardial infarctions that can be prognostically important with no radiation. Together with its ability to detect ventricular thrombus, edema and inflammation, CMR is a compelling alternative test and furthermore, allows monitoring of revascularization procedures' success. Currently there exist more software tools to quantitate and display scar burden by PET but we can anticipate that this advantage will rapidly evaporate since this is now a focus of activity of software development. Intracellular contrast agents currently under investigation may more readily identify areas with reversible ischemia by CMR.

Ischemia and infarct imaging by $\mathrm{CT}$ is now becoming feasible with the latest generation CT equipment. This technology needs to be assessed and compared with standard tests. The combination of coronary anatomy and myocardial abnormalities is only possible by CMR and CT. Coronary anatomy visualization is currently more robust with $\mathrm{CT}$ and easier to obtain. We anticipate that myocardial imaging with CT will be an active area of research for the next few years.

In addition to accuracy, the costs of tests affect their utilization. PET is relatively expensive in this regard. Nevertheless, the bar has been raised by the Centers for Medicare and Medicaid Services (CMS) in the US for the acceptance of new technologies. In order for a new test to be reimbursed by CMS, the test needs to demonstrate that its use positively improves patient outcomes particularly in the form of randomized controlled trials. There is currently the strongest outcome data in the echo and nuclear imaging literature although there is a growing body of supporting literature for CMR. It is likely that most countries will similarly require outcome data for acceptance. Thus we anticipate that more outcome studies will be a focus of future research.

Open Access This article is distributed under the terms of the Creative Commons Attribution Noncommercial License which permits any noncommercial use, distribution, and reproduction in any medium, provided the original author(s) and source are credited.

\section{References}

1. The Joint European Society of Cardiology/American College of Cardiology (2000) Myocardial infarction redefined-a consensus document of The Joint European Society of Cardiology/American College of Cardiology 
Committee for the redefinition of myocardial infarction. Eur Heart J 21:1502-1513

2. Alpert JS, Thygesen K, Antman E, Bassand JP (2000) Myocardial infarction redefined-a consensus document of The Joint European Society of Cardiology/American College of Cardiology Committee for the redefinition of myocardial infarction. J Am Coll Cardiol 36:959-969

3. Thygesen K, Alpert JS, White HD (2007) Universal definition of myocardial infarction. J Am Coll Cardiol 50:2173-2195

4. Thygesen K, Alpert JS, White HD (2007) Universal definition of myocardial infarction. Eur Heart $\mathrm{J} 28$ : 2525-2538

5. Thygesen K, Alpert JS, White HD et al (2007) Universal definition of myocardial infarction. Circulation 116: 2634-2653

6. Fox KA, Birkhead J, Wilcox R, Knight C, Barth J (2004) British cardiac society working group on the definition of myocardial infarction. Heart 90:603-609

7. Cannon CP, Gibson CM, Lambrew CT et al (2000) Relationship of symptom-onset-to-balloon time and doorto-balloon time with mortality in patients undergoing angioplasty for acute myocardial infarction. JAMA 283: 2941-2947

8. Antman EM, Hand M, Armstrong PW et al (2008) 2007 focused update of the ACC/AHA 2004 guidelines for the management of patients with ST-elevation myocardial infarction: a report of the American College of Cardiology/American Heart Association Task Force on Practice Guidelines. J Am Coll Cardiol 51:210-247

9. Kannel WB (1986) Silent myocardial ischemia and infarction: insights from the Framingham Study. Cardiol Clin 4:583-591

10. Menown IB, Mackenzie G, Adgey AA (2000) Optimizing the initial 12-lead electrocardiographic diagnosis of acute myocardial infarction. Eur Heart J 21:275-283

11. Sgarbossa EB (2000) Value of the ECG in suspected acute myocardial infarction with left bundle branch block. J Electrocardiol 33(Suppl):87-92

12. Hiss RG, Lamb LE, Allen MF (1960) Electrocardiographic findings in 67, 375 asymptomatic subjects. X. Normal values. Am J Cardiol 6:200-231

13. Zimetbaum PJ, Josephson ME (2003) Use of the electrocardiogram in acute myocardial infarction. $\mathrm{N}$ Engl $\mathrm{J}$ Med 348:933-940

14. Ito H, Okamura A, Iwakura K et al (1996) Myocardial perfusion patterns related to thrombolysis in myocardial infarction perfusion grades after coronary angioplasty in patients with acute anterior wall myocardial infarction. Circulation 93:1993-1999

15. Dong J, Ndrepepa G, Schmitt C et al (2002) Early resolution of ST-segment elevation correlates with myocardial salvage assessed by Tc- $99 \mathrm{~m}$ sestamibi scintigraphy in patients with acute myocardial infarction after mechanical or thrombolytic reperfusion therapy. Circulation 105:2946-2949

16. Kim JS, Ko YG, Yoon SJ et al (2008) Correlation of serial cardiac magnetic resonance imaging parameters with early resolution of ST-segment elevation after primary percutaneous coronary intervention. Circ J 72: $1621-1626$
17. Rouan GW, Lee TH, Cook EF, Brand DA, Weisberg MC, Goldman L (1989) Clinical characteristics and outcome of acute myocardial infarction in patients with initially normal or nonspecific electrocardiograms (a report from the Multicenter Chest Pain Study). Am J Cardiol 64: 1087-1092

18. Lloyd-Jones DM, Camargo CA Jr, Lapuerta P, Giugliano RP, O’Donnell CJ (1998) Electrocardiographic and clinical predictors of acute myocardial infarction in patients with unstable angina pectoris. Am J Cardiol 81:1182-1186

19. Cannon CP, McCabe CH, Stone PH et al (1997) The electrocardiogram predicts one-year outcome of patients with unstable angina and non-Q wave myocardial infarction: results of the TIMI III Registry ECG Ancillary Study. Thrombolysis in Myocardial Ischemia. J Am Coll Cardiol 30:133-140

20. de Zwaan C, Bar FW, Janssen JH et al (1989) Angiographic and clinical characteristics of patients with unstable angina showing an ECG pattern indicating critical narrowing of the proximal LAD coronary artery. Am Heart J 117:657-665

21. McCann CJ, Glover BM, Menown IB et al (2008) Novel biomarkers in early diagnosis of acute myocardial infarction compared with cardiac troponin T. Eur Heart J 29:2843-2850

22. Jaffe AS, Babuin L, Apple FS (2006) Biomarkers in acute cardiac disease: the present and the future. J Am Coll Cardiol 48:1-11

23. Morrow DA, Cannon CP, Rifai N et al (2001) Ability of minor elevations of troponins I and $\mathrm{T}$ to predict benefit from an early invasive strategy in patients with unstable angina and non-ST elevation myocardial infarction: results from a randomized trial. JAMA 286:2405-2412

24. Antman EM, Anbe DT, Armstrong PW et al (2004) ACC/ AHA guidelines for the management of patients with STelevation myocardial infarction: a report of the American College of Cardiology/American Heart Association Task Force on Practice Guidelines (Committee to Revise the 1999 Guidelines for the Management of Patients with Acute Myocardial Infarction). Circulation 110:e82-e292

25. Eagle KA, Goodman SG, Avezum A, Budaj A, Sullivan CM, Lopez-Sendon J (2002) Practice variation and missed opportunities for reperfusion in ST-segment-elevation myocardial infarction: findings from the Global Registry of Acute Coronary Events (GRACE). Lancet 359: 373-377

26. Fox KA (2004) An international perspective on acute coronary syndrome care: insights from the Global Registry of Acute Coronary Events. Am Heart J 148:S40-S45

27. Keeley EC, Boura JA, Grines CL (2003) Primary angioplasty versus intravenous thrombolytic therapy for acute myocardial infarction: a quantitative review of 23 randomised trials. Lancet 361:13-20

28. McNamara RL, Herrin J, Bradley EH et al (2006) Hospital improvement in time to reperfusion in patients with acute myocardial infarction, 1999 to 2002. J Am Coll Cardiol 47:45-51

29. Vaccarino V, Rathore SS, Wenger NK et al (2005) Sex and racial differences in the management of acute myocardial infarction, 1994 through 2002. N Engl J Med 353: 671-682 
30. Zijlstra F (2003) Angioplasty vs thrombolysis for acute myocardial infarction: a quantitative overview of the effects of interhospital transportation. Eur Heart J 24: $21-23$

31. Larose E, Cote J, Rodes-Cabau J et al (2009) Contrastenhanced cardiovascular magnetic resonance in the hyperacute phase of ST-elevation myocardial infarction. Int J Cardiovasc Imaging 25:519-527

32. Patel MR, Dehmer GJ, Hirshfeld JW, Smith PK, Spertus JA (2009) ACCF/SCAI/STS/AATS/AHA/ASNC 2009 appropriateness criteria for coronary revascularization: a report of the American College of cardiology foundation appropriateness criteria task force, society for cardiovascular angiography and interventions, society of thoracic surgeons, American Association for thoracic surgery, American Heart Association, and the American Society of Nuclear Cardiology: endorsed by the American Society of Echocardiography, the heart failure society of America, and the society of cardiovascular computed tomography. Circulation 119:1330-1352

33. Steen H, Giannitsis E, Futterer S, Merten C, Juenger C, Katus HA (2006) Cardiac troponin T at 96 hours after acute myocardial infarction correlates with infarct size and cardiac function. J Am Coll Cardiol 48:2192-2194

34. Heller GV, Stowers SA, Hendel RC et al (1998) Clinical value of acute rest technetium-99 m tetrofosmin tomographic myocardial perfusion imaging in patients with acute chest pain and nondiagnostic electrocardiograms. J Am Coll Cardiol 31:1011-1017

35. Hilton TC, Thompson RC, Williams HJ, Saylors R, Fulmer H, Stowers SA (1994) Technetium-99 m sestamibi myocardial perfusion imaging in the emergency room evaluation of chest pain. J Am Coll Cardiol 23: $1016-1022$

36. Kontos MC, Jesse RL, Anderson FP, Schmidt KL, Ornato JP, Tatum JL (1999) Comparison of myocardial perfusion imaging and cardiac troponin $I$ in patients admitted to the emergency department with chest pain. Circulation 99:2073-2078

37. Kontos MC, Jesse RL, Schmidt KL, Ornato JP, Tatum JL (1997) Value of acute rest sestamibi perfusion imaging for evaluation of patients admitted to the emergency department with chest pain. J Am Coll Cardiol 30: 976-982

38. Stowers SA, Eisenstein EL, Th Wackers FJ et al (2000) An economic analysis of an aggressive diagnostic strategy with single photon emission computed tomography myocardial perfusion imaging and early exercise stress testing in emergency department patients who present with chest pain but nondiagnostic electrocardiograms: results from a randomized trial. Ann Emerg Med 35:17-25

39. Tatum JL, Jesse RL, Kontos MC et al (1997) Comprehensive strategy for the evaluation and triage of the chest pain patient. Ann Emerg Med 29:116-125

40. Udelson JE, Beshansky JR, Ballin DS et al (2002) Myocardial perfusion imaging for evaluation and triage of patients with suspected acute cardiac ischemia: a randomized controlled trial. JAMA 288:2693-2700

41. Varetto T, Cantalupi D, Altieri A, Orlandi C (1993) Emergency room technetium-99 m sestamibi imaging to rule out acute myocardial ischemic events in patients with nondiagnostic electrocardiograms. J Am Coll Cardiol 22:1804-1808

42. Mahmarian JJ, Dakik HA, Filipchuk NG et al (2006) An initial strategy of intensive medical therapy is comparable to that of coronary revascularization for suppression of scintigraphic ischemia in high-risk but stable survivors of acute myocardial infarction. J Am Coll Cardiol 48: 2458-2467

43. Mahmarian JJ, Shaw LJ, Filipchuk NG et al (2006) A multinational study to establish the value of early adenosine technetium-99 m sestamibi myocardial perfusion imaging in identifying a low-risk group for early hospital discharge after acute myocardial infarction. J Am Coll Cardiol 48:2448-2457

44. Mahmarian JJ, Shaw LJ, Olszewski GH, Pounds BK, Frias ME, Pratt CM (2004) Adenosine sestamibi SPECT post-infarction evaluation (INSPIRE) trial: a randomized, prospective multicenter trial evaluating the role of adenosine Tc-99 $\mathrm{m}$ sestamibi SPECT for assessing risk and therapeutic outcomes in survivors of acute myocardial infarction. J Nucl Cardiol 11:458-469

45. Moore B, Pitts S, Sasson C, Eisner R, Sigman S, Patterson $R$ (2007) Chest Pain evaluation in the emergency department: A new application for positron emission tomographic $[\mathrm{PET}\} \mathrm{Rb}-82$ myocardial perfusion imaging. J Nucl Med 48(Suppliment 2):213P

46. Abbott BG, Liu YH, Arrighi JA (2007) [18F]Fluorodeoxyglucose as a memory marker of transient myocardial ischaemia. Nucl Med Commun 28:89-94

47. He ZX, Shi RF, Wu YJ et al (2003) Direct imaging of exercise-induced myocardial ischemia with fluorine-18labeled deoxyglucose and Tc-99 m-sestamibi in coronary artery disease. Circulation 108:1208-1213

48. Jain D, He ZX (2008) Direct imaging of myocardial ischemia: a potential new paradigm in nuclear cardiovascular imaging. J Nucl Cardiol 15:617-630

49. Dilsizian V, Bateman TM, Bergmann SR et al (2005) Metabolic imaging with beta-methyl-p-[(123)I]-iodophenyl-pentadecanoic acid identifies ischemic memory after demand ischemia. Circulation 112:2169-2174

50. Kawai Y, Morita K, Nozaki Y, Ohkusa T, Sakurai M, Tamaki N (2004) Diagnostic value of 123I-betamethyl-piodophenyl-pentadecanoic acid (BMIPP) single photon emission computed tomography (SPECT) in patients with chest pain. Comparison with rest-stress $99 \mathrm{mTc}$-tetrofosmin SPECT and coronary angiography. Circ J 68: 547-552

51. Kawai Y, Tsukamoto E, Nozaki Y, Morita K, Sakurai M, Tamaki N (2001) Significance of reduced uptake of iodinated fatty acid analogue for the evaluation of patients with acute chest pain. J Am Coll Cardiol 38: 1888-1894

52. Cohen M, Kervokian R, Boissonnet C et al (1997) Ana'lisis de los recurso utilizados en el manejo del dolor precordial. Rev Argent Cardiol 65:41-54

53. Lee TH, Rouan GW, Weisberg MC et al (1987) Clinical characteristics and natural history of patients with acute myocardial infarction sent home from the emergency room. Am J Cardiol 60:219-224

54. Stark ME, Vacek JL (1987) The initial electrocardiogram during admission for myocardial infarction. Use as a 
predictor of clinical course and facility utilization. Arch Intern Med 147:843-846

55. Cheitlin MD, Armstrong WF, Aurigemma GP et al (2003) ACC/AHA/ASE 2003 guideline update for the clinical application of echocardiography-summary article: a report of the American College of Cardiology/American Heart Association Task Force on Practice Guidelines (ACC/AHA/ASE Committee to Update the 1997 Guidelines for the Clinical Application of Echocardiography). J Am Coll Cardiol 42:954-970

56. Beller GA (1988) Myocardial perfusion imaging for detection of silent myocardial ischemia. Am J Cardiol $61: 22 \mathrm{~F}-28 \mathrm{~F}$

57. Tomaszuk-Kazberuk A, Sobkowicz B, Kaminski K et al (2008) Myocardial perfusion assessed by contrast echocardiography correlates with angiographic perfusion parameters in patients with a first acute myocardial infarction successfully treated with angioplasty. Can J Cardiol 24:633-639

58. Hillis GS, Mulvagh SL, Pellikka PA et al (2003) Comparison of intravenous myocardial contrast echocardiography and low-dose dobutamine echocardiography for predicting left ventricular functional recovery following acute myocardial infarction. Am J Cardiol 92:504-508

59. Pellikka PA, Nagueh SF, Elhendy AA, Kuehl CA, Sawada SG (2007) American Society of Echocardiography recommendations for performance, interpretation, and application of stress echocardiography. J Am Soc Echocardiogr 20:1021-1041

60. Bountioukos M, Elhendy A, van Domburg RT et al (2004) Prognostic value of dobutamine stress echocardiography in patients with previous coronary revascularisation. Heart 90:1031-1035

61. Douglas PS, Khandheria B, Stainback RF et al (2008) ACCF/ASE/ACEP/AHA/ASNC/SCAI/SCCT/SCMR 2008 appropriateness criteria for stress echocardiography: a report of the American College of Cardiology Foundation Appropriateness Criteria Task Force, American Society of Echocardiography, American College of Emergency Physicians, American Heart Association, American Society of Nuclear Cardiology, Society for Cardiovascular Angiography and Interventions, Society of Cardiovascular Computed Tomography, and Society for Cardiovascular Magnetic Resonance endorsed by the Heart Rhythm Society and the Society of Critical Care Medicine. J Am Coll Cardiol 51:1127-1147

62. Sicari R, Picano E, Landi P, Pasanisi E, Venneri L (2004) Pharmacologic stress echocardiography predicts total mortality early after acute myocardial infarction. J Am Soc Echocardiogr 17:114-120

63. Sicari R, Picano E, Landi P et al (1997) Prognostic value of dobutamine-atropine stress echocardiography early after acute myocardial infarction. Echo Dobutamine International Cooperative (EDIC) Study. J Am Coll Cardiol 29:254-260

64. Jennings RB, Reimer KA (1991) The cell biology of acute myocardial ischemia. Annu Rev Med 42:225-246

65. Sage MD, Jennings RB (1988) Myocyte swelling and plasmalemmal integrity during early experimental myocardial ischemia in vivo. Scanning Microsc 2:477-484
66. Arheden H, Saeed M, Higgins CB et al (1999) Measurement of the distribution volume of gadopentetate dimeglumine at echo-planar MR imaging to quantify myocardial infarction: comparison with 99mTc-DTPA autoradiography in rats. Radiology 211:698-708

67. Kim RJ, Fieno DS, Parrish TB et al (1999) Relationship of MRI delayed contrast enhancement to irreversible injury, infarct age, and contractile function. Circulation 100:1992-2002

68. Thornhill RE, Prato FS, Wisenberg G, Moran GR, Sykes J (2004) Determining the extent to which delayedenhancement images reflect the partition-coefficient of Gd-DTPA in canine studies of reperfused and unreperfused myocardial infarction. Magn Reson Med 52: 1069-1079

69. Wagner A, Mahrholdt H, Thomson L et al (2006) Effects of time, dose, and inversion time for acute myocardial infarct size measurements based on magnetic resonance imaging-delayed contrast enhancement. J Am Coll Cardiol 47:2027-2033

70. Kim RJ, Albert TS, Wible JH et al (2008) Performance of delayed-enhancement magnetic resonance imaging with gadoversetamide contrast for the detection and assessment of myocardial infarction: an international, multicenter, double-blinded, randomized trial. Circulation 117: 629-637

71. Rochitte CE, Lima JA, Bluemke DA et al (1998) Magnitude and time course of microvascular obstruction and tissue injury after acute myocardial infarction. Circulation 98:1006-1014

72. Wu KC, Kim RJ, Bluemke DA et al (1998) Quantification and time course of microvascular obstruction by contrastenhanced echocardiography and magnetic resonance imaging following acute myocardial infarction and reperfusion. J Am Coll Cardiol 32:1756-1764

73. Lima JA, Judd RM, Bazille A, Schulman SP, Atalar E, Zerhouni EA (1995) Regional heterogeneity of human myocardial infarcts demonstrated by contrast-enhanced MRI. Potential mechanisms. Circulation 92:1117-1125

74. Lockie T, Nagel E, Redwood S, Plein S (2009) Use of cardiovascular magnetic resonance imaging in acute coronary syndromes. Circulation 119:1671-1681

75. Abdel-Aty H, Zagrosek A, Schulz-Menger J et al (2004) Delayed enhancement and T2-weighted cardiovascular magnetic resonance imaging differentiate acute from chronic myocardial infarction. Circulation 109: 2411-2416

76. Brown JJ, Peterson TM, Slutsky RA (1985) Regional myocardial blood flow, edema formation, and magnetic relaxation times during acute myocardial ischemia in the canine. Invest Radiol 20:465-471

77. Simonetti OP, Finn JP, White RD, Laub G, Henry DA (1996) "Black blood" T2-weighted inversion-recovery MR imaging of the heart. Radiology 199:49-57

78. Slutsky RA, Brown JJ, Peck WW, Strich G, Andre MP (1984) Effects of transient coronary ischemia and reperfusion on myocardial edema formation and in vitro magnetic relaxation times. J Am Coll Cardiol 3:1454-1460

79. Stork A, Lund GK, Muellerleile K et al (2006) Characterization of the peri-infarction zone using T2-weighted 
MRI and delayed-enhancement MRI in patients with acute myocardial infarction. Eur Radiol 16:2350-2357

80. Schulz-Menger J, Gross M, Messroghli D, Uhlich F, Dietz R, Friedrich MG (2003) Cardiovascular magnetic resonance of acute myocardial infarction at a very early stage. J Am Coll Cardiol 42:513-518

81. Aletras AH, Tilak GS, Natanzon A et al (2006) Retrospective determination of the area at risk for reperfused acute myocardial infarction with T2-weighted cardiac magnetic resonance imaging: histopathological and displacement encoding with stimulated echoes (DENSE) functional validations. Circulation 113:1865-1870

82. Dymarkowski S, Ni Y, Miao Y et al (2002) Value of t2weighted magnetic resonance imaging early after myocardial infarction in dogs: comparison with bis-gadolinium-mesoporphyrin enhanced T1-weighted magnetic resonance imaging and functional data from cine magnetic resonance imaging. Invest Radiol 37:77-85

83. DeLuca AJ, Kaplan S, Aronow WS et al (2006) Comparison of prevalence of unrecognized myocardial infarction and of silent myocardial ischemia detected by a treadmill exercise sestamibi stress test in patients with versus without diabetes mellitus. Am J Cardiol 98: 1045-1046

84. Feringa HH, Karagiannis SE, Vidakovic R et al (2007) The prevalence and prognosis of unrecognized myocardial infarction and silent myocardial ischemia in patients undergoing major vascular surgery. Coron Artery Dis 18:571-576

85. Kwong RY, Sattar H, Wu H et al (2008) Incidence and prognostic implication of unrecognized myocardial scar characterized by cardiac magnetic resonance in diabetic patients without clinical evidence of myocardial infarction. Circulation 118:1011-1020

86. Wagner A, Mahrholdt H, Holly TA et al (2003) Contrastenhanced MRI and routine single photon emission computed tomography (SPECT) perfusion imaging for detection of subendocardial myocardial infarcts: an imaging study. Lancet 361:374-379

87. Kwong RY, Schussheim AE, Rekhraj S et al (2003) Detecting acute coronary syndrome in the emergency department with cardiac magnetic resonance imaging. Circulation 107:531-537

88. Cury RC, Shash K, Nagurney JT et al (2008) Cardiac magnetic resonance with $\mathrm{T} 2$-weighted imaging improves detection of patients with acute coronary syndrome in the emergency department. Circulation 118:837-844

89. Plein S, Greenwood JP, Ridgway JP, Cranny G, Ball SG, Sivananthan MU (2004) Assessment of non-ST-segment elevation acute coronary syndromes with cardiac magnetic resonance imaging. J Am Coll Cardiol 44: 2173-2181

90. Ingkanisorn WP, Kwong RY, Bohme NS et al (2006) Prognosis of negative adenosine stress magnetic resonance in patients presenting to an emergency department with chest pain. J Am Coll Cardiol 47:1427-1432

91. Mahrholdt H, Wagner A, Judd RM, Sechtem U (2002) Assessment of myocardial viability by cardiovascular magnetic resonance imaging. Eur Heart J 23:602-619

92. Choi CJ, Haji-Momenian S, Dimaria JM et al (2004) Infarct involution and improved function during healing of acute myocardial infarction: the role of microvascular obstruction. J Cardiovasc Magn Reson 6:917-925

93. Engelmann MG, Theiss HD, Hennig-Theiss $C$ et al (2006) Autologous bone marrow stem cell mobilization induced by granulocyte colony-stimulating factor after subacute ST-segment elevation myocardial infarction undergoing late revascularization: final results from the G-CSF-STEMI (Granulocyte Colony-Stimulating Factor ST-Segment Elevation Myocardial Infarction) trial. J Am Coll Cardiol 48:1712-1721

94. Lund GK, Stork A, Muellerleile K et al (2007) Prediction of left ventricular remodeling and analysis of infarct resorption in patients with reperfused myocardial infarcts by using contrast-enhanced MR imaging. Radiology 245:95-102

95. Masci PG, Dymarkowski S, Rademakers FE, Bogaert J (2009) Determination of regional ejection fraction in patients with myocardial infarction by using merged late gadolinium enhancement and cine MR: feasibility study. Radiology 250:50-60

96. Hombach V, Grebe O, Merkle N et al (2005) Sequelae of acute myocardial infarction regarding cardiac structure and function and their prognostic significance as assessed by magnetic resonance imaging. Eur Heart J 26:549-557

97. O'Regan DP, Ahmed R, Karunanithy N et al (2009) Reperfusion hemorrhage following acute myocardial infarction: assessment with $\mathrm{T} 2 *$ mapping and effect on measuring the area at risk. Radiology 250:916-922

98. Kim RJ, Wu E, Rafael A et al (2000) The use of contrastenhanced magnetic resonance imaging to identify reversible myocardial dysfunction. N Engl J Med 343: 1445-1453

99. Schvartzman PR, Srichai MB, Grimm RA et al (2003) Nonstress delayed-enhancement magnetic resonance imaging of the myocardium predicts improvement of function after revascularization for chronic ischemic heart disease with left ventricular dysfunction. Am Heart J 146:535-541

100. Wellnhofer E, Olariu A, Klein C et al (2004) Magnetic resonance low-dose dobutamine test is superior to SCAR quantification for the prediction of functional recovery. Circulation 109:2172-2174

101. Gutberlet M, Frohlich M, Mehl S et al (2005) Myocardial viability assessment in patients with highly impaired left ventricular function: comparison of delayed enhancement, dobutamine stress MRI, end-diastolic wall thickness, and TI201-SPECT with functional recovery after revascularization. Eur Radiol 15:872-880

102. Bodi V, Sanchis J, Lopez-Lereu MP et al (2005) Usefulness of a comprehensive cardiovascular magnetic resonance imaging assessment for predicting recovery of left ventricular wall motion in the setting of myocardial stunning. J Am Coll Cardiol 46:1747-1752

103. Barmeyer AA, Stork A, Bansmann M et al (2008) Prediction of myocardial recovery by dobutamine magnetic resonance imaging and delayed enhancement early after reperfused acute myocardial infarction. Eur Radiol 18:110-118

104. Srichai MB, Junor C, Rodriguez LL et al (2006) Clinical, imaging, and pathological characteristics of left ventricular thrombus: a comparison of contrast-enhanced 
magnetic resonance imaging, transthoracic echocardiography, and transesophageal echocardiography with surgical or pathological validation. Am Heart J 152:75-84

105. Friedrich MG, Sechtem U, Schulz-Menger J et al (2009) Cardiovascular magnetic resonance in myocarditis: a JACC White Paper. J Am Coll Cardiol 53:1475-1487

106. Gutberlet M, Spors B, Thoma T et al (2008) Suspected chronic myocarditis at cardiac MR: diagnostic accuracy and association with immunohistologically detected inflammation and viral persistence. Radiology 246: 401-409

107. Eitel I, Behrendt F, Schindler K, Gutberlet M, Schuler G, Thiele H (2009) Takotsubo cardiomyopathy or myocardial infarction? Answers from delayed enhancement magnetic resonance imaging. Int J Cardiol 135:e9-e12

108. Eitel I, Desch S, Sareban M et al (2009) Prognostic significance and magnetic resonance imaging findings in aborted myocardial infarction after primary angioplasty. Am Heart J 158:806-813

109. Eitel I, Lucke C, Grothoff M et al (2010) Inflammation in takotsubo cardiomyopathy: insights from cardiovascular magnetic resonance imaging. Eur Radiol 20:422-431

110. Hecht HS (2008) Applications of multislice coronary computed tomographic angiography to percutaneous coronary intervention: how did we ever do without it? Catheter Cardiovasc Interv 71:490-503

111. Kachenoura N, Gaspar T, Lodato JA et al (2009) Combined assessment of coronary anatomy and myocardial perfusion using multidetector computed tomography for the evaluation of coronary artery disease. Am J Cardiol 103:1487-1494

112. Choe YH, Choo KS, Jeon ES, Gwon HC, Choi JH, Park JE (2008) Comparison of MDCT and MRI in the detection and sizing of acute and chronic myocardial infarcts. Eur J Radiol 66:292-299

113. Nieman K, Cury RC, Ferencik M et al (2006) Differentiation of recent and chronic myocardial infarction by cardiac computed tomography. Am J Cardiol 98:303-308

114. Nikolaou K, Knez A, Sagmeister S et al (2004) Assessment of myocardial infarctions using multidetector-row computed tomography. J Comput Assist Tomogr 28: 286-292

115. Nikolaou K, Sanz J, Poon M et al (2005) Assessment of myocardial perfusion and viability from routine contrastenhanced 16-detector-row computed tomography of the heart: preliminary results. Eur Radiol 15:864-871

116. Higgins CB, Siemers PT, Schmidt W, Newell JD (1979) Evaluation of myocardial ischemic damage of various ages by computerized transmission tomography. Time- dependent effects of contrast material. Circulation 60: 284-291

117. Gerber BL, Belge B, Legros GJ et al (2006) Characterization of acute and chronic myocardial infarcts by multidetector computed tomography: comparison with contrast-enhanced magnetic resonance. Circulation 113: 823-833

118. Lardo AC, Cordeiro MA, Silva C et al (2006) Contrastenhanced multidetector computed tomography viability imaging after myocardial infarction: characterization of myocyte death, microvascular obstruction, and chronic scar. Circulation 113:394-404

119. Schuleri KH, Centola M, George RT et al (2009) Characterization of peri-infarct zone heterogeneity by contrast-enhanced multidetector computed tomography: a comparison with magnetic resonance imaging. J Am Coll Cardiol 53:1699-1707

120. Jacquier A, Boussel L, Amabile N et al (2008) Multidetector computed tomography in reperfused acute myocardial infarction. Assessment of infarct size and noreflow in comparison with cardiac magnetic resonance imaging. Invest Radiol 43:773-781

121. Habis M, Capderou A, Ghostine S et al (2007) Acute myocardial infarction early viability assessment by 64slice computed tomography immediately after coronary angiography: comparison with low-dose dobutamine echocardiography. J Am Coll Cardiol 49:1178-1185

122. Boussel L, Ribagnac M, Bonnefoy E et al (2008) Assessment of acute myocardial infarction using MDCT after percutaneous coronary intervention: comparison with MRI. AJR Am J Roentgenol 191:441-447

123. Sato A, Hiroe M, Nozato T et al (2008) Early validation study of 64-slice multidetector computed tomography for the assessment of myocardial viability and the prediction of left ventricular remodelling after acute myocardial infarction. Eur Heart J 29:490-498

124. Blankstein R, Okada DR, Rocha-Filho JA, Rybicki FJ, Brady TJ, Cury RC (2009) Cardiac myocardial perfusion imaging using dual source computed tomography. Int $\mathrm{J}$ Cardiovasc Imaging

125. George RT, Silva C, Cordeiro MA et al (2006) Multidetector computed tomography myocardial perfusion imaging during adenosine stress. J Am Coll Cardiol 48: 153-160

126. Paul JF, Dambrin G, Caussin C, Lancelin B, Angel C (2003) Sixteen-slice computed tomography after acute myocardial infarction: from perfusion defect to the culprit lesion. Circulation 108:373-374 